\title{
Computer-based collaborative revision as a virtual lab of editorial/literary translation genetics
}

\section{Giovanna Scocchera}

University of Bologna at Forlì, Italy

giovanna.scocchera@unibo.it

Introducing revision as a key stage of any writing process, including translation, this paper aims at underlining its role in the genetics of translation. Other-revision, i.e. the activity performed by a reviser on someone else's translation, will be the focus of this paper, whose overall objective is to show that when performed in a collaborative modality, revision may prove a miniature, virtual lab of translation genetics. With the aid of computer tools already available, and new ad-hoc solutions hopefully to be developed, all reviser-translator interplay in the form of text changes, suggestions and comments can be visually tracked, recorded and thus become an object of study. Besides being an invaluable didactic tool and a hoped-for professional practice, computer-based collaborative revision may prove a valid method for data elicitation and collection, and for experimental investigation in the field of translation genetics.

\section{Introduction}

While in Translation Studies a first, general distinction can be made between research in the process of translation and in its product, it all doubles when thinking of translation from a genetics point of view. As a matter of fact, two different processes exist, each leading to its own product: the process towards the translator's delivery of what he/she considers his/her best to the job commissioner or customer, and the subsequent stage or stages in which professionals other than the translator are involved (the reviser being one of them), leading to the final version of a translation.

Both processes and products in pragmatic translation have been thoroughly investigated over the last half a century or so from various approaches and perspectives within Translation Process Research (e.g., Breedveld, 2002; Englund Dimitrova, 2005; Hansen, 2013; Künzli, 2009; Parra Galiano, 2007a/b; Robert, 2013, 2014), and Writing/Editing Studies (e.g., Allal, Chanquoy, \& Largy, 2004; Bryant, 2002; Chesnet \& Alamargot, 2005; Horning, 2002; Horning \& Becker, 2006; Roussey \& Piolat, 2008). The particular case of editorial/literary translation and 
revision, however, has rarely been the object of scholarly research, with very few exceptions such as Jones (2006) and Kolb (2013), both investigating the general processes and personal procedures enacted by literary translators of poetry and fiction respectively; Buzelin (2007), who explored the subject from a Latourian perspective in her study of three literary translations "in the making"; Bogic (2010) who analyzed the translator-publisher relationships during the translation process into English of Simone de Beauvoir's Le deuxième sexe; and Siponskonski (2013), who studied unpublished avant-textes of Shakespeare's translations into Finnish by highlighting negotiation between translators and copyeditors and strongly advocating for the inclusion of editorial work as a subject of study in translation research. In line with Siponskonski's research, this paper focuses on editorial/literary translation revision as a privileged time and space for negotiation between one's own and other's translation attitudes, approaches and solutions, as well as for decision-making at both textual and extra-textual level. Revision undeniably plays a key role in the making of a text, be it original writing - where it is commonly, but not limitedly, referred to as "editing" (Mossop, 2001, 2014; Pym, 2011) - or translation, and when the revision activity is tracked and recorded in all its constituents (text additions, omissions, replacements, shifts, alterations, comments, suggestions, translator-reviser interaction on translation issues), it may represent a treasure trove of research and study material for translation genetics.

By complementing scholarly research contributions with firsthand data collected through a survey on the professional practice of editorial/literary revision in Italy (Scocchera, 2015), this paper will deal with the work of translators and revisers on the translations submitted to publishers, with a particular focus on collaborative revision as the virtual place where both reviser and translator take an active role in the genesis of the published text. It is in this virtual lab that textual progress is exposed, thus enabling researchers to observe not only translation approaches, attitudes and practices, but also analytical, critical, evaluative competences and interpersonal relationships.

Finally, when this collaborative activity is performed as an electronically situated practice and what takes place between translator and reviser is fully tracked and recorded (a few examples from an authentic revision job will be provided), it produces both quantitative and qualitative data eligible for study, analysis and triangulation with data elicited through other research methods. This paper ultimately aims at showing how computer-based collaborative revision, far from being a publishing extravaganza, should consistently figure not only as a didactic tool in translation education and training, but also as a valid addition to experimental investigation methodologies currently available, possibly creating a corpus of "tracked" documents to be used as research material in translation studies and in translation genetics. 


\section{Terminological notes on revision}

In its etymology, the word "revision" - from the Latin revisere and the late Latin revidere - embraces the two complementary meanings of "seeing anew", i.e. to see again either something or somebody, and to see with new eyes. This further "view" on the object is what basically happens whenever a draft editorial translation is getting ready for publication: the author of the translation goes through his/her work a second, third, maybe even a fourth time, before submitting it to the publisher, hopefully having each time a new, fresh look on what he/she has done. A fully fresh vision, however, can only be guaranteed by the reviser who, seeing the text for the first time, works on the text from a privileged vantage point, looking at it with a detachment the translator is usually incapable of. The reviser's "naivety" as a reader allows him/her to perform the revising activity by combining professional expertise on the text - correcting, improving or suggesting alternatives - with a focused attention on its acceptability as a publishing product and its potential reception among final readers.

A brief, bilingual overview of Italian and English definitions of the terms "revisione" and "revision" shows interesting nuances in their general meaning and usage. ${ }^{1}$ In addition to the widely accepted idea of revision as the activity of checking, correcting and generally improving a text before considering it final, the same term is also used to refer to the assessment of a vehicle or piece of machinery to make sure it works properly. To revise something may also involve adjusting or updating it, in order to meet different time- or culture-related requirements. While these acceptations may also apply to some extent to the translation context (a translated text needs to "work" as a well-oiled and efficient machine in the publishing market and old translations often need to sound and look younger, both in linguistic and cultural terms), it is worth illustrating how revision and revision-related terms are more specifically defined within Translation Studies as well as in the professional context. A first line can be drawn between self-revision and other-revision (Mossop, 2001, 2014; Pym, 2011), where the former is carried out by the translator on his/her own translation, either as a separate stage in the translation process or as an on-going problem-solving and decisionmaking activity, carried out both on a "mental" level (Mossop, 2001, 2014) or on a physical support, be it paper or screen. Other-revision is the set of operations enacted by a reviser in order to correct any mistakes or omissions, suggest improvements and alternative solutions, provide support and feedback and make sure the text complies with the publisher's requirements and with potential readers' needs and expectations. This first conceptual dichotomy applies to any translation type and context, however its terms are commonly addressed in different ways. While a thorough overview of revision terminology and a newly formulated, summative definition of revision are provided in Scocchera 
(2015), here only quick reference will be made to the pseudo-synonyms used in everyday translation practice. Within the European quality standard EN 15038, for example - a set of process and product requirements translation service providers need to conform with if they want to be acknowledged as quality providers - self-revision is referred to as "checking" and other-revision is referred to as "revision" when involving ST/TT comparative analysis, "review" when it implies only TT reading and checking. A comprehensive overview of revision terminology in the context of translation quality is provided in English by Brunette (2000) and in German by Künzli (2014).

In the editorial/literary context, instead - both in English and non-English speaking countries - "editing" and "copy-editing" are often misused as synonyms for revision, sometimes indicating exactly the same kind of textual activity, sometimes mistaking the thorough comparative analysis and textual operations revision consists of with surface changes aimed at guaranteeing conformity to the publisher's house style (copyediting), or with in-depth, structural and stylistic changes carried out on a translated text not necessarily viewed as a translation (editing). An exhaustive illustration of these definitions and what they stand for is provided in Mossop $(2001,2014)$ and Paul (2009).

If considered in the context of original writing and composition, "revision" tends to be used when referring to structural and content changes, while "editing" refers "to the correction of mechanical features of writing, as spelling, punctuation, capitalization, etc." (Harris \& Hodges, 1995, p.68). On more general terms, revision is described as

the interaction of conscious and unconscious choices writers make in a draft as they weave readable writing for readers, drawing on a balance of several kinds of self-awareness and on specific skills to produce the finished fabric of a readable text. (Horning, 2002, p. 5)

Finally, focusing on its evaluative, corrective and decision-making role, revision is regarded as a fundamental process in all kinds of written productions:

It requires going back over the text at least once for evaluation purposes, and making changes in the text to correct whatever problems were detected during the evaluation. [...] this basic cognitive architecture can be broken down into various subprocesses (task definition, evaluation, strategy selection, text and/or text-plan modification) which require knowledge [...] and which lead to the construction of mental representations. (Roussey \& Piolat, 2008, p. 765) 


\section{Translation revision in theory}

What follows is a brief, non-exhaustive selection of some key concepts in revision, here introduced to support an idea of revision as the place of negotiation and change par excellence, where a translation moves from embryo to fully-fledged entity. A basic illustration of scholarly literature in translation revision will also be provided, underlining specific strengths and weaknesses of research approaches and methodologies.

\subsection{Key concepts in translation revision}

The birth and further development of the concept of revision is effectively outlined in Lee (2006), who identifies in Nida the first translation scholar to have shown awareness of the key role of revision work - with particular reference to Bible translation - as well as its difficulties:

Revisions are in some ways a good deal more difficult than original translations, and hence often involve very complex procedures, usually because of vested interests (Nida, 1964, p. 245)

However, it is only thanks to Munday (2001) that the term "revision" becomes manifest in his version of the Translation Studies map built upon the seminal work by Holmes (1972). What Holmes defined as "translation criticism", in Munday's map articulates into three different forms: reviews, evaluation of translation, revision.

When thinking of the key concepts in translation revision, regardless of textual types and contexts, one cannot but mention the comparative element, featuring in most definitions of revision and felt as a pre-requisite of any critical and evaluative activity, as indicated by Reiss (2000):

[...] translation criticism is possible only by persons who are familiar with both the target and source languages, and is accordingly in a position to compare the translation directly with its original. In brief, translation criticism requires a comparison of the target and source texts (p. 3)

Another core issue in revision, especially in other-revision where a translator's work is submitted to the reviser's evaluation and then corrected/amended accordingly, is the issue of objectivity. If we are to agree with Delisle (1988), the control and evaluation stage coming as the third and last step of a translation cognitive process - whose aim is to confirm the accuracy of translation strategies and solutions adopted should be read as "a function of the interpretation that preceded re- 
expression", and as a matter of fact as "a form of interpretation" in its own right (p. 66). In other words, a second interpretation taking place after the reformulation stage and before the final choice is made. This view of the control and evaluation stage as a new interpretation takes on a whole different light and meaning when the control and evaluation activity - that is the revision proper - is performed by someone who is not the translator and can therefore make his/her own choices and interventions on the grounds of an interpretation of both the source text and translated text, that is different from the translator's.

As underlined by Gile (1995) in his sequential model of translation, the reviser follows a reformulation loop that starts with the translated text - and not with the source text, as it is for the translator - by assessing its suitability for publication and the accuracy in relation to the source text. While carrying out this assessment activity closely linked with the quality of the translation, its role in the target market and culture, the translator's status and reputation, the reviser may be required to follow also a comprehension - and therefore interpretation - loop. In this case, "revision can be said to follow in a way a process going in the direction opposite to that followed by the translation process itself." (Gile, 1995, p. 111)

Subjectivity of comprehension and interpretation may therefore lead to a subjectivity of reformulation, and this is the reason behind situations in which revisers may want to "impose their own linguistic preferences at the expense of the translator's decision." (Künzli, 2007a, p. 124)

To overcome the translator's frustration at having to undergo an "alien" revision, and the reviser's frustration at being considered the translator's arch-enemy, Chakhachiro, (2005) - as well as Horguelin and Brunette (1998) and Mossop (2001, 2014) - strongly advocates for translatorreviser communication:

The revisers' emendations and their discussions with or reports to the original translator should be systematic in order to control their own subjectivity and achieve consensus about an outcome that is acceptable to all parties concerned. (p. 227)

By underlining the decision-making aspect, Chakhachiro manages to bring together different dimensions of revision (interpretative, analytical and corrective ones), also adding further descriptive and constructive elements.

Decision-making in revision involves interpretation of sourcetext messages, determination of the style and the audiences of the source and target texts, the identification of the semantic and 
stylistic problems in target texts, a description of problems when there is a need for a reviser's report, and suggestions for alternatives. (p. 235)

The idea of a reviser's feedback where translation problems and solutions are illustrated to the translator's benefit is closely linked to another core issue in revision, that is the definition of revision competence and its components. Although overlapping to some extent with a more general definition of translation competence, whereby a reviser is a professional with the same knowledge and skills as the translator's but raised "à la puissance $n$ " (Horguelin \& Brunette, 1998) the seminal research work carried out by Hansen $(2009 \mathrm{a} / \mathrm{b})$ identifies revision competence specificity, describing it as follows:

A necessary attitude regarding revision is fairness, and necessary skills are attentiveness as to pragmatic, linguistic and stylistic phenomena and errors, the ability to abstract or distance oneself from one's own and others' previous formulations and the ability to explain and argue for changes (2009b, p. 323)

The declarative and explanatory sub-competence described by Hansen is at its most effective when jointly applied with what Künzli (2006) identifies in his three-pronged model as interpersonal competence, that is "the ability to collaborate with the different actors involved in a translation project: translators, revisers, translation companies, commissioners and/or source-text authors" (pp. 11-12). An example of these sub-competences at work will be provided through the authentic translation revision extracts illustrated in section 6 .

Finally, being an evaluative, corrective and ameliorative activity, revision is inevitably linked with the idea of quality and the need for shared quality standards and parameters. An interesting overview of theoretical and general principles about quality and the quality parameters used in revision, especially within international linguistic contexts, is provided by Hernández Morin (2009b), while Parra Galiano (2007b) identifies a set of quality revision procedure, principles and parameters whereby the reviser should:

1. know the translation brief;

2. read the TT as if it was an original text;

3. assess the feasibility/profitability of the revision job;

4. decide on the revision parameters and degree required by the TT;

5. reduce revision interventions to a minimum;

6. justify revision interventions;

7. acknowledge his/her responsibility (pp. 201-202, my translation) 
This check-list strictly refers to the translation service provision and translation industry contexts and can only be partially applied in editorial/literary translation. As a matter of fact, the freelance reviser working for a publisher on a revision job does not often receive a translation or revision brief, and is not expected to work out the revision profitability or to keep revision interventions to a minimum. Regardless of time and fees allowed, the reviser is expected to proceed with a ST/TT comparative check, which does not necessarily result in a feedback report where revision interventions are explained and/or justified to the translator. A first attempt to identify quality revision procedures and parameters in the editorial context was made in Italy by STRADE, the Italian Association of Editorial Translators, who in 2013 defined a set of "Guidelines for the Translation Production Process" (www.traduttoristrade.it/decalogo/english), believing that full transparency and mutual respect on the part of all the professionals involved are guarantee of quality translator-reviser relationships and quality end-products. Among its main points are: the importance of early contact between translator and reviser; the foreign language skills of the reviser, the need to submit the revised translation to the translator so that he/she can accept/refuse/discuss any changes made; constant communication among all the professionals involved in translation publishing.

\subsection{Overview of research on translation revision}

Besides focusing on the key concepts illustrated above, scholarly research has closely investigated revision carrying out descriptive, empirical and experimental studies to better understand what happens during this stage of the translation process. Through technology-supported investigation methods such as think-aloud protocols (TAPs), eye-tracking, keystroke logging, screen logging and other, quantitative data have been elicited and collected on translational behavior in an experimental situation, and also on specific issues arising during the revision stage. ${ }^{2}$

When dealing with other-revision in particular, most of these methods have been employed to understand the role different revision procedures and strategies (monolingual TT reading vs. comparative ST/TT check or different combinations of both) have on the final revision output (Robert, 2008, 2012, 2013, 2014). Similarly, other features of the other-revision process have been studied such as a combination of TT reading-aloud and ST/TT comparative check by the reviser (Rochard, 2002); the ST/TT reading order before revision; the revision time/revision quality ratio; the incidence of necessary vs. non-necessary revision changes and finally the importance of specialist knowledge in revision (Künzli, 2005, 2006, 2009). TAPs have also been employed to investigate ethical aspects of the revision activity (Künzli, 2007b), revealing the 
complex relationships between the actors involved in the translation and revision process and the arising ethical conflicts and dilemmas, often magnified by the "relative anonymity that characterizes the interpersonal relationships" (p. 44).

More recently, scholarly research has started to focus on the didactic aspects of revision, viewed not only as a tool in translation teaching and education (Mossop, 2001, 2014; Séguinot, 1991), but also as a self-standing teaching content. Having identified what characterizes revision competence compared to a more general translation competence (Hansen, 2009a/b), and considering the ever-changing nature of the translation market, especially the translation publishing market where inhouse training in editing, revision and copy-editing is no longer available (Kruger, 2008), there is an increasing need for revision-specific teaching and training opportunities as well as for the formulation of ad-hoc contents, tools and methods. Despite the still limited number of academically-based revision courses all over the world, specific objectives and contents have been identified, among others, by Mossop (1992), Hine (2003), Schjoldager, Rasmussen \& Thomsen (2008) and Künzli (2006). Moreover, as part of revision-teaching material, parameters check-lists and guidelines have been successfully developed by Horguelin and Brunette (1998), Mossop (2001, 2014), Parra Galiano (2007b) and Lee (2006).

In an attempt to investigate revision process and product from a wider perspective and to account for the complex cognitive and psychosociological activities involved in human revision, qualitative empirical studies represent a precious methodological addition (Hansen, 2010), as they can collect rich data also on the agents of revision (translators, revisers, copy-editors and their strategies, attitudes and behaviours). A further asset of qualitative investigation methods is their greater "naturalness" compared to the average experimental set-ups of Translation Process Research studies. As with Hansen (2010)

Human translation processes are complex mental processes occurring in social contexts. Any type of study that tries to decompose such processes into constituent isolated phenomena and then observe and analyze them separately under "controlled" conditions simply in order to guarantee more exact results would run the risk of changing the character of these "natural processes" and distort any results gained (p. 193)

A few examples of qualitative research in revision are provided in the study by Shih (2006) which, although focusing on self-revision, investigates some key aspects of the revision process (revision cycles, drawer time, most frequent types of textual operations, procedures employed) eliciting and collecting data through translator interviews. The same method is used by Sorvali (1998) to investigate creativity within the 
translation process and by Jones (2006) to understand the texttransformation mechanisms in poetry translation.

The choice of empirical and qualitative research methods is also at the basis of a recently conducted study on the professional practice of editorial/literary translation revision in Italy (Scocchera, 2015). Through two separate, mostly open-ended questionnaires addressing revised translators and revisers respectively, the study aimed at collecting data on three main investigation parameters regarding the agents of revision (gender, age, educational and professional background, working experience) the revision product (evaluation of the revision output, identification of revision needs and types of intervention) and the revision process (time management, revision behaviours and procedures and their frequency of occurrence, revision objectives and expectations). Following Lasswell's communication model as survey structure, both questionnaires were articulated into five main investigation areas to collect information on the what, who, how, where and when, and why of editorial/literary translation revision. By asking questions arising from academic research, professional practice and education in revision (a total of 27 and 38 questions for revised translators and revisers respectively), the survey elicited, collected and produced valuable data on issues at the core of the research design:

- is there a shared definition of revision?

- what is the professional profile of a translation reviser in Italy?

- does specific education/training in revision exists?

- what revision procedures are mostly used in professional practice?

- $\quad$ are there particularly successful or unsuccessful ones?

- what is the aim of revision?

- what kind of relationship exists between translator and reviser?

A selection of data thus collected from the questionnaires (a total of 80 questionnaires fully completed and returned via on-line survey platform or e-mail, from 55 translators and 25 revisers respectively) will be illustrated and commented upon in the section below.

\section{The professional practice of editorial/literary translation revision in Italy}

"In an ideal world, translators should be their own editors combining an unlimited knowledge with a literary gift as well as - last but not least - a critical sense which would allow them to remove or simply avoid any mistakes and errors they might make. Were this possible, the publishers would simply love such translators. " (Fordoński, 2014, p. 167)

The reality of editorial and literary translation, however, is not populated with all-knowing translators, but rather with "human" 
translators whose work will always need revision by someone else. In other-revision, a professional other than the translator- an in-house or freelance reviser- works on the translated text to improve and/or correct it, to point out shortcomings and suggest alternative solutions, but hopefully also to praise strengths and successful strategies. Although styles, patterns and procedures may differ according to such variables as revision brief, publisher's house style, textual genre, target readership or other, the importance of revision in the making of a published translation is a shared belief.

The following paragraphs are meant to provide an overview of other-revision as a professional activity by offering insights from professionals and first-hand data collected through the survey illustrated in the section above, with particular reference to the translator/reviser relationship, their professional interplay as recorded on files (through tracked changes, comments and/or notes) and how this plays a potentially valuable role in translation genetics.

\subsection{The revised translator's point of view}

Revised translators tend to have a negative attitude towards revision (see for example the interviews collected in Carmignani, 2008, and Manfrinato, 2008), possibly due to bad experiences with revisers who are said to destroy months of painstaking work in the name of such dogmatic principles as Fluency and Readability at all costs. In her Sul tradurre, the award-winning translator from English into Italian Susanna Basso (2010) shares with the readers one of such negative experiences where the publisher chose to "update" an existing translation to bring it closer to the cultural and linguistic taste of the target market:

I did not like the revision done on my translation. It was a rushed and unscrupolous job. I did not agree on the decision to write in an updated version of Austen's Italian (as if such thing existed) and to do so by questionably and randomly dismiss the use of subjunctive or introduce a more modern vocabulary in order to achieve a better fluency and ease of reading that I simply regarded as an impoverishment in language quality (p. 119, my translation)

When revisions are not the result of mutual agreement between translator and reviser, consequences are twice as negative: on the one hand they jeopardize the necessary mutual trust and respect that is paramount in the translator-reviser relationship; on the other, they affect the quality of the final product which, as with Basso,

betrays the negotiation efforts between the parties involved. The language and style of the translation become uneven, 
discontinuous, depending on who had the upper hand on deciding revision changes and corrections. (p. 119, my translation)

The same point of view is shared by Petruccioli (2014), who provides a detailed analysis of revised texts where translator-reviser relationship has been difficult or null. The revision troubles become apparent on the revised translation, which Petruccioli describes as "a tale of inner conflicts: a story told in jolts, sometimes smooth and sometimes ragged, sometimes far too plain and sometimes totally obscure. In other words, an incoherent mishmash." (p. 87, my translation).

All things considered, the different degrees of unease that all translators feel when their translation work undergoes revision is quite inevitable: what they have done as professionals becomes a mirror of what they are as individuals, or at least this is how they perceive it. Translators know that their relationship with the text is far deeper than what they can expect from the reviser, but after all the reviser's detachment from the translated text is what allows him/her to provide the translation with something new and, possibly, better. There might be jealousy on both sides, and because of these tensions and negative feelings translators think of revision as a censoring and spoiling activity, rather than a maieutic act aimed at bringing forward the qualities of the translation, praising its strengths and suggesting further improvements. However, although the translator-revisers relationship is perceived as a tug of war, rather than a fruitful collaboration, it is generally called and hoped for, thus confirming its necessary role in the road towards a final, published version.

Evidence of this is provided by data showing that translators "leave traces" on their translated text for the reviser, sometimes to explain a daring choice, sometimes to highlight an unsolved translation problem, sometimes to ask for suggestion. As a matter of fact, although translators do not necessarily need to resort to change-tracking of their translations during self-revision, the survey on the revision of editorial/literary translation in Italy (Scocchera, 2015, see 3.2) reveals that $76.4 \%$ of responding translators use comments which are meant either for themselves as a reminder, to highlight something worth double-checking, to make a note of a quote or a reference $(38 \%)$; or are specifically left for the benefit of the reviser $(52 \%)$ in order to share doubts or difficulties, to justify translation strategies and/or choices, to inform about ST inconsistencies or factual mistakes. The remaining percentage of respondents uses comments for both purposes.

If these figures are a sign of the translator's openness towards the reviser, in professional revision there seems to be little room for real translator/reviser collaboration, as shown in the figure below: $43.6 \%$ of responding translators never have contacts with the reviser during the revision stage; the same percentage of respondents claim they always 
liaise with the reviser; the remaining $12.6 \%$ say that translator-reviser dialogue takes place only occasionally.

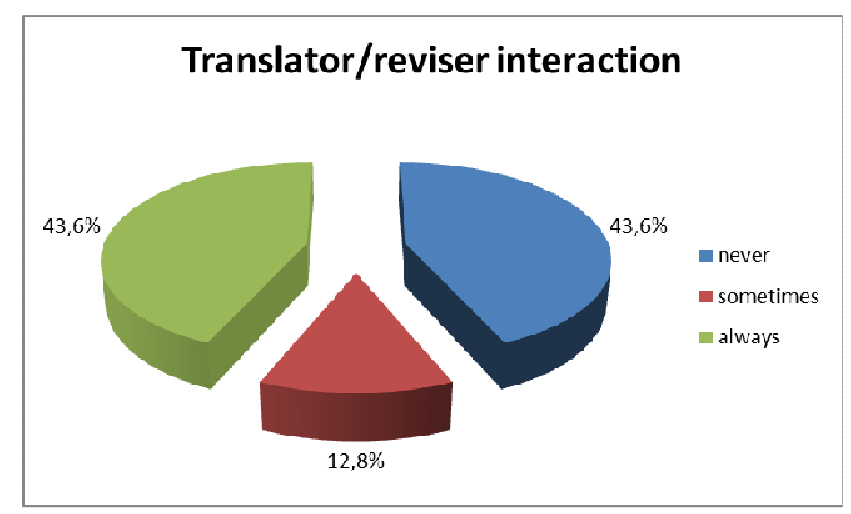

Figure 1: Translator/Reviser interaction - translators' point of view

To encourage higher translator/reviser interaction would not only comply with a need strongly felt by most translators but would also represent an important first step towards improved professional relationships built on mutual knowledge and respect. Within a translation genetics perspective, it would also mean creating further opportunities for both translator and reviser to express their own poetics, their strategic approach to translation, and to illustrate the rationale behind their creative process.

\subsection{The reviser's point of view}

In the Italian publishing market, translators still have to struggle if they want to be publicly and economically acknowledged, and it is not uncommon that their name does not appear on the book cover or first pages. Revisers, though, are even more invisible. Not only do their names ever appear among the contributors of a published translation, but their activity on the text must be invisible too: a good revision shouldn't be heard or seen in the translated text. Finally, the reviser's invisibility can be literal when the publisher decides that a translated text can be published with no need of revision, a case which is far from being uncommon.

Data collected in the above-mentioned survey show that in the genesis of a published translation, the revision stage is intended by revisers mainly as a linguistic activity, aimed at correcting formal mistakes and making the text more fluent and in line with the readers' expectations and knowledge of the world. In other words, an activity 
focused on "acceptability" (Toury, 1980) of the target text, and much closed to the concept of editing or copy-editing of a non-translational text (Mossop, 2001, 2014; Pym, 2011).

As part of the survey, revisers were asked to indicate on which textual and linguistic elements they more frequently work on during revision. Out of the 25 respondents, eleven (44\%) did not identify specific problem-areas and said they usually dealt with a wide spectrum of linguistic, stylistic, translational and copy-editing issues (problems of interpretation, author's tone and voice syntax, fluency, calques, rhythm, sound effects, misprints,) while those who underlined specific types of textual intervention indicated the following as those most frequently carried out: correction of interpretation mistakes (22\%) fluency (13\%), syntax and calques $(11 \%)$, misprints $(9 \%)$ rhythm/repetitions/copyediting issues (7\%), word choice and lexical accuracy $(6 \%)$ and finally inconsistencies or problems of tone $(3.5 \%)$

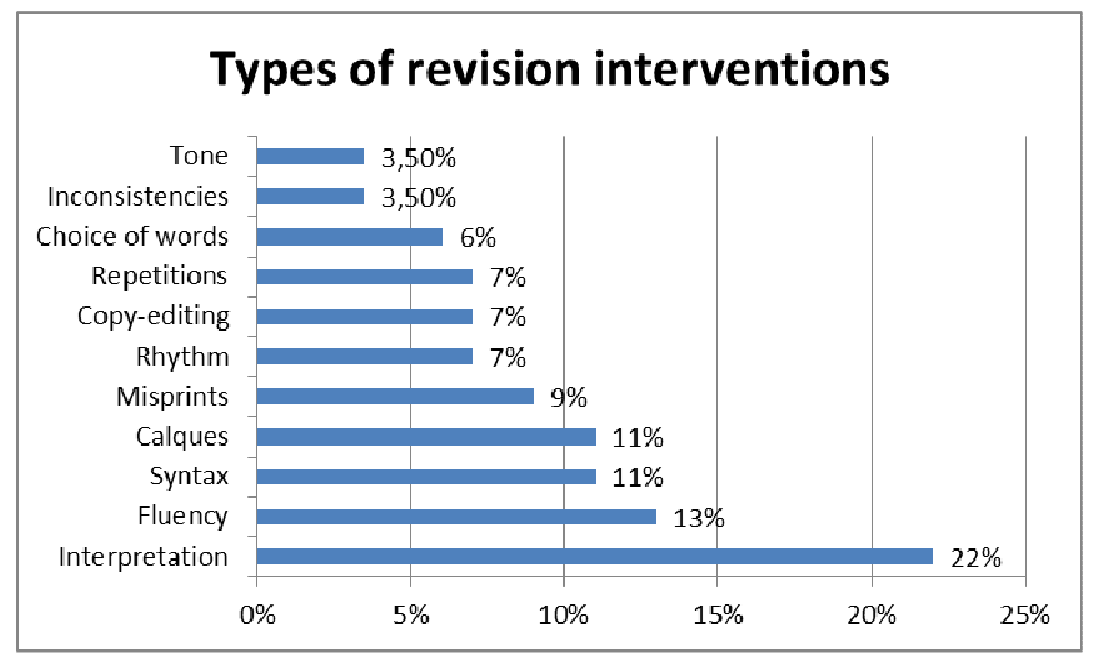

Figure 2: Most frequent types of revision interventions - revisers' point of view

As much as translators, revisers too were asked to answer questions on their interaction with translators during the revision stage. Answers show that only $32 \%$ of them regularly interact with translators, while $44 \%$ of them rarely or never do so. The remaining 24\% (6 out of 25) get in touch with translators only on given occasions, that is to unknot interpretation doubts or to find agreement on specific solutions, but not as a general practice. Overall, for $68 \%$ of the revisers the translator is not a privileged counterpart to deal and discuss with during the revision activity, thus confirming data collected on the translators' side and showing that collaborative revision is hardly the norm in the Italian publishing market. 


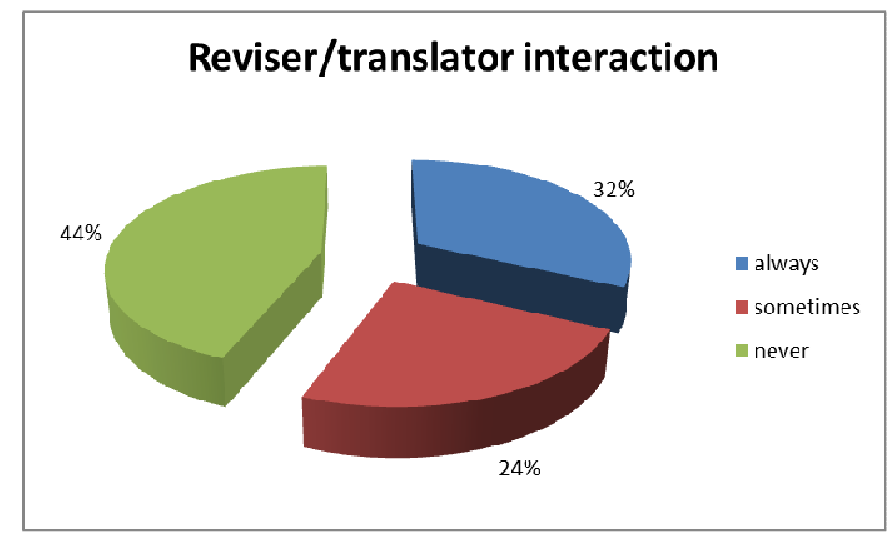

Figure 3: Reviser/Translator interaction - revisers' point of view

\section{The role of collaborative revision in translation genetics}

As shown by data collected through the survey above, in collaborative revision - especially when revision changes are tracked, commented, and explained -the making of the text is out in the open. This magnifying glass on what happens in revision is likely to expose not only linguistic, textual or translation issues, but also editorial, personal and professional attitudes, thus unveiling what lies behind a translation and its genesis.

If the aim of genetic criticism since its foundation by Hay and institutionalization with ITEM in the Seventies is to unveil the process of artistic creation by observing and analyzing what text producers do and how this relates with the complex polysystem they belong to, the study of the revision process and product, as well as the translator-reviser relationships not only exposes a key stage in the creative process of the translated text but it also brings to surface any linguistic, stylistic, aesthetic, social and professional issues may intervene in the problemsolving and decision-making activity it consists of. If the object of genetic criticism "is not the existing documents but the movement of writing that must be inferred from them" (Deppman, 2004, p. 2), in analyzing the record of a collaborative translation revision - where the reviser's textual interventions are shown together with any additional comment, explanation, justification he/she may have provided and the ensuing response by the translator - the researcher may infer several "movements of writing", namely the translator's, the reviser's and a third process leading to an agreed, third piece of writing that is the revised translation.

Hay's idea of a plurality of processes and texts and their diachronous development, where "writing is not simply consummated in the written work" and the text is just "a manifestation of a process which is always virtually present in the background, a kind of third dimension of the written work" (Hay, 1988, p. 75, in Deppman, 2004, p. 5) is all the 
more true when the process and its product concern translation revision. Since in the revision of a translation we witness textual interventions, correction of mistakes, suggestion of alternative strategies and solutions and any relevant supporting/contrasting evidence, as a matter of fact we witness that "meaningful variation" that the genetic critic will want to see in his object of study (Deppman, 2004, p. 11).

As with Munday (2013), the analysis of translation avant-textes including the record of a translation revision - can give "potentially unrivalled insights into translator decision-making" (p. 125). All the more so, where translator-reviser collaboration, dialogue and exchanges exist and are well documented, they can reveal a wealth of information on the translation process, strategies and attitudes, but also about professional and personal points of view and emotions, as well as editorial and publishing trends at large. Having the opportunity to observe, analyze and study not only the final product of revision, but also the road that leads to that final result, is like entering the virtual lab of translation genetics and view translation from a vantage point where both process and product with all the underlying progress stages, interim steps, and interpersonal relationships - are exposed. This idea of revision and its output as a virtual lab corresponds to De Biasi's definition of a rough draft in a literary production which "can be considered as a sort of text laboratory, in which it becomes possible to piece back together an essential phase of the writer's work" (de Biasi, 2007). The author adds that

the rough draft enables us to be present at the birth of the motivations, strategies and metamorphoses of writing, which more often than not, labours precisely at effacing its own tracks, and at rendering its mechanisms untraceable, secret or problematic in the completed form of the definitive text. (de Biasi, 2007)

The added value of collaborative revision is that the information it provides is not only around the text and its actual birth, but also around the agents involved, namely translator and reviser, the relationship with each other, with other publishing professionals and with the world around them. As with Buzelin (2007)

analyzing the process of translation from the viewpoint of a work's manufacture allows for documenting the editorial and revision work done on the manuscript delivered by the translators and thereby better understanding the role of actors who participate in the making of the text but whose actions and practices have so far received little attention (p. 141)

The same interest in the process of translation and its interim products as well as in any other complementary data and information by and around 
the translators is at the basis of the work by Romanelli (2013) on the genesis of the Italian translations of 114 poems by Emily Dickinson.

However, if collaborative revision is to have any scientific value as a means for data production and collection, a sound and effective research methodology is needed. First of all, collaborative revision can provide researchers with a macro-experimental set up which is real, rather than realistic, thus making the data obtained reliable and usable, also in triangulation with other sets of data elicited through other research methods. Moreover, when revision is carried out as an electronicallysituated practice, it proves an efficient means to comply with the need to keep a tracked record of all the variables in the translation process, thus overcoming bias and prejudices against the unreliability of avant-texte materials, as claimed by Filippalopoulou (2008): "paper drafts and notes tend to be "messy documents [...] loose sheets of paper, designed to serve a short-term purpose" (p. 28).

Although computer-based collaborative revision cannot fully unveil either the genetic process leading to the translator's output submitted to revision, or the process behind the reviser's output submitted to the translator for acceptance/refusal (in the real world, translator and reviser do not normally keep an electronically tracked record of their own translation/revision process and interim products), the translator-reviser interaction has the power to make underlying and unspoken problemsolving and decision-making activities emerge. The log of this "electronic dialogue" allows to follow the progress of a translation towards publication by creating at the same time a corpus of data that remain available in the long term. Again with Munday (2013), "the existence of other material $[\ldots]$ and, most particularly, correspondence, may provide clear evidence about the negotiation and location of power in the publishing world" and "the drafts [but also a record of collaborative revision] should be seen as real-time and real-world evidence of translation revisions and doubts, sometimes with a rationale for decisionmaking. They constitute visible traces of the translatorial act." (p. 134)

A final supporting evidence of the potential value of collaborative revision as a means of data elicitation and collection and its fruitful application in translation genetics comes from the research work by Pavlović, N. (2009) and Pavlović, T. (2013) on "collaborative translation protocols" (CTPs). The former researcher defines them as:

a product of collaborative translation tasks, i.e. those tasks in which a pair or group of people translate the same source text together, basing their decisions on mutual consensus. In such tasks, the understanding of the source text meaning and the creation of the target text occur after individual cognitive processing and the interaction among the members of the group. (p. 83) 
Again, compared to other investigation methods, CTPs guarantee increased naturalness of situation (because the dialogue between different translation participants is natural and real) and the reduction of stress that subjects usually undergo in an experimental situation. Participant interaction is not prompted by the researcher but is the result of the collaborative endeavor itself. And it is because of this interactive nature that participants are motivated to "express, comment on and even justify their strategies in the process of negotiating solutions for problems" (Barbosa \& Neiva, 2003, p. 152), thus making CTPs a valuable tool to elicit qualitatively and quantitatively richer data than with other research methodologies as "the two (or more) subjects translating together have to justify the suggestions they make and to criticize the suggestions made by their partners(s)". (Göpferich \& Jääskeläinen, 2009, p. 171)

When applying all this to the revision stage of the translation process, the recorded dialogue between the participants in a collaborative translation project is replaced by the tracked record of translator-reviser interaction on an electronic file: the definition of "collaborative translation protocols" (CTPs) may be then slightly changed into "collaborative revision protocols" (CRPs). However, while CTPs record an on-line dialogue, "collaborative revision protocols" keep a record of a virtual, rather than real communication exchange, as the translator-reviser written dialogue takes place off-line. This is extremely important in terms of research validity: while CTPs present some critical aspects in that

the mental processes they reflect differ from the mental processes of an individual who translates alone, who does not have to take social interaction into account and who is not influenced, either positively or negatively, by the ideas of his or her partner (Göpferich \& Jääskeläinen, 2009, p. 172)

the off-line, translator-reviser exchange in "collaborative revision protocols" is a series of individual processes, both mental and operational ones, whereby participants respond and react to inputs and prompts in their own time and according to their own line of reasoning, without being subject to external pressures.

With all this in mind, it seems fair to encourage the practice of collaborative revision not only as ethically correct and respectful of both the translator' and the reviser's individuality, but also as a protocol in Translation Process Research investigation, by virtue of its assets compared to other data elicitation and collection tools and methods and also for the wide range of information on the process, product and agents of translation and revision it allows to infer. 


\section{1 Computer-based collaborative revision}

Collaborative revision has been extensively described in this paper as an ideal means to expose the various steps of growth, evolution or involution of a published translation, and to unveil its bouts of creativity, its critical stages, its necessary compromises. But for all this to be usable in scholarly research, especially in the field of translation genetics, it needs to leave its traces somewhere. As with de Biasi (2011),

the genesis of a work must have left some "traces", that is the material evidence that textual genetics seeks to find, interpret and understand through the manuscripts. (p. 21, my translation)

The advent of both typewriter and word-processing software has somehow discouraged the production of translation interim versions, saving both translator and reviser endless drafts to be marked and corrected with pen and pencils and allowing simple text overwriting. Computer technology, however, has only partly impacted on the production of material to be used in genetics research. As a matter of fact it allows for creating electronic files where the actual revision activity can be recorded and subsequently worked and commented upon, also choosing among different text viewing and highlighting modalities. This is the case of Microsoft Word Revision, a basic yet useful toolkit when revising a text in that it offers key features such as editing, change tracking, and commenting that can be easily switched on and off. It is therefore possible to have, in one file, a tracked record of several stages and actions: notes and comments left by translators to support his/her own translation strategies and solutions; the reviser's changes on the text (omissions, additions, substitutions, permutations), his/her suggested alternatives, notes, comments and responses to the translator's comments; the translator/reviser exchange and any other subsequent textual intervention. Even the narrow space of a computer screen can host a wealth of information: the translator's choices, the reviser's corrections and /or suggestions, the translator's agreement or disagreement. In creating a "log" of the revision activity and thus providing written evidence of what goes on during a crucial stage of a translation creative process, the application of this IT tool allows to overcome bias on the partiality and unreliability of extra-textual materials and interim translation products (Toury, 1995).

In corroboration of all this, an authentic example of computerbased collaborative revision is here illustrated with the help of a few screenshots showing revision files and the translator-reviser interaction on them. I was entrusted with the revision job by the Italian publisher Einaudi and asked to proceed as usual with the revision of the translation and then to submit the revision output to the translator. But it turned out to be much more complicated than this, as the original text was "The 
Kraus project" and its author was Jonathan Franzen. The "story" of this revision job, as well as the genesis of the published translation, is a peculiar one: the English "original" is in fact Franzen's translation of a German essay by the notoriously difficult and obscure Viennese satirist Karl Kraus. Franzen appears not only as a translator from German, but also as an original author, as he complements the translation with a rich corpus of end-notes, which are both explanatory of the translated text and a narrative device in their own right. The Italian publisher decided to provide readers with an Italian translation of Kraus' essay directly from German (by translator Claudio Groff) and with an Italian translation of Franzen's notes from English (by translator Silvia Pareschi).

The obvious difficulties arising during the translation stage (the coherent oneness of Franzen-translator and Franzen-author was actually broken, so that the notes Pareschi was translating from English referred to an English text that no longer existed, because it was replaced by an Italian version translated from German) were magnified during revision: the Kraus-Franzen duet became in revision a quartet consisting of Kraus' voice and his translator's and Franzen's voice and his translator's. My job was to make these four voices sing in harmony, also respecting the inbuilt relationships between texts and their authors/translators. What is particularly worth underlining, here, is that the computer-based collaborative revision modality, where the translation revision is submitted to the translator for his/her approval/refusal/discussion, keeps record of a very long and complex negotiation stage accompanying the genesis of the published translation. The examples provided below concern the search for balance between the language used by Franzen as author and the language used by Franzen as translator; the need for cultural adaptation; the coherence and consistency between translation choices by the two Italian translators; the need to provide Italian readers with a text that can be loyal to all its authors (Kraus, Franzen, Groff, Pareschi.)

Regarding the relationship between the Italian translation from German and the Italian translation of the English notes, it is interesting to note that Pareschi wrote a separate document where she pointed out linguistic and/or semantic problems arising from the lack of a single author and a single translator in the Italian version. This example of avant-texte records a first stage in the translation genesis: the comparative check between the Italian translation from German and the relevant notes translated from English, to make sure that this complex operation did not lead to discrepancies or lexical/semantic incoherencies, and, if necessary, to suggest alternative solutions. The figure below shows notes on how a perfectly right Italian translation from German does not work any more when combined with a quotation translated from the English notes or, in another instance, how it jeopardizes the semantic value of the English original text. In a third instance, the translator expresses the need for a shared translation choice. 


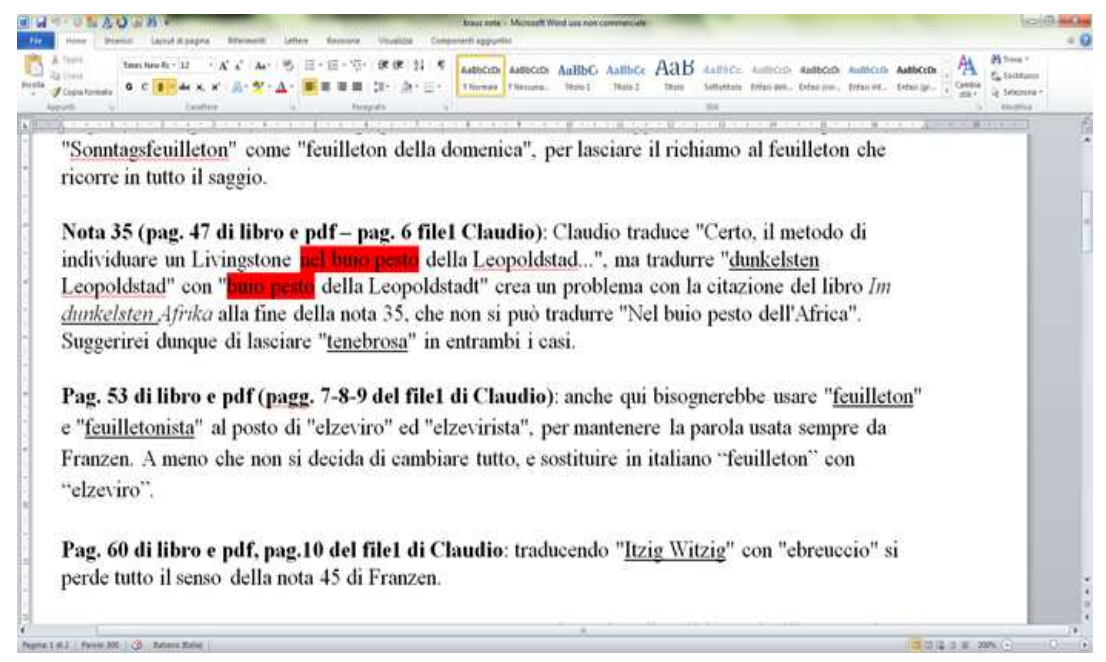

Figure 4: Example of collaborative revision avant-texte - Notes written by the Italian translator from English to the Italian translator from German on linguistic/semantic issues.

As for the collaborative revision stage, the few examples provided should be able to show how the possibility to keep a tracked record of the translator-reviser dialogue, the revision interventions, their acceptance/refusal and any other additional comment, produces an impressive corpus of quantitative and qualitative data on the translation genesis. In the figure below, the different colors in both text and comment sections clearly show the translator and reviser participation in the revision stage; the extent to which revision interventions are accepted/refused; the subject and tone of the comments. The reviser's interventions in the text are purple, while the translator's subsequent changes are in light blue. The proportion between the reviser's interventions and their acceptance/refusal by the translator can also be taken into account as an important element in the genesis of a translation, to indicate for example different levels of expertise or different levels of power between translator and reviser. 


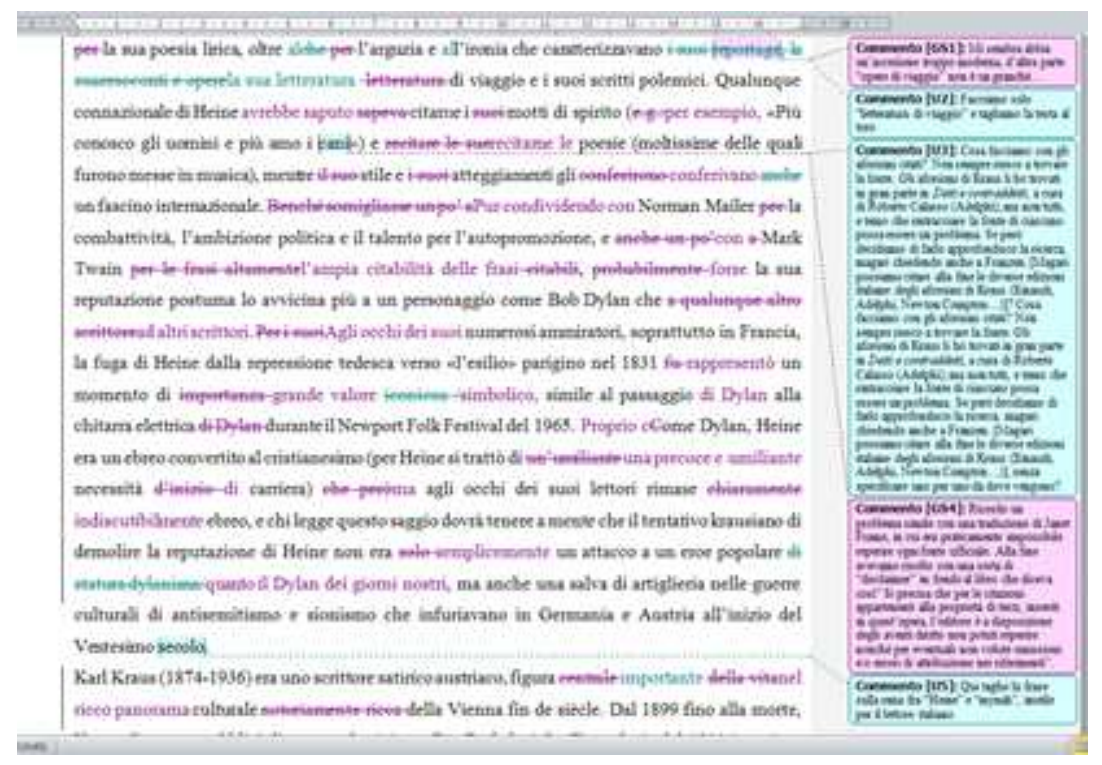

Figure 5: Example of tracked collaborative revision - revision interventions \& comments

As for the comments on the right-end margin, the first in purple contains the reviser's justification of a suggested lexical alternative, to be preferred in order to avoid an anachronistic effect of the language. The second comment, in light blue, records the translator's partial acceptance of the suggested alternative and relevant motivation. In the third comment, also in light blue, the translator raises a copy-editing question, that is the need to find a number of quotations in their official Italian translation and the relevant sources and, where missing, to provide service translations, the problem being compliance with coherence and uniformity as required by the publisher's house-style guidelines. The reviser's response in purple tells about a similar case previously encountered in her professional experience and suggests a possible solution that is satisfactory both in terms of accuracy and uniformity. This exchange appears particularly interesting from a translation genetics point of view: translator and reviser take into account both textual and extra-textual factors in shaping a shared final version of the translation and they device strategies and solutions together. In the last light-blue comment, the translator informs the reviser of a deliberate omission, due to a sound effect that cannot be recreated in Italian.

In the figure below, comments refer to yet another stage in the genesis of a translation, that is the translator asking the author for linguistic/semantic explanations, the author's reply, the translator-reviser exchange on the subject and the reviser's proposed solution, eventually accepted by the translator. It seems a particularly precious "trace" as it shows the author's direct contribution to the genesis of the translation, as well as his attitude as a writer and the respectful relationship with his translator. 


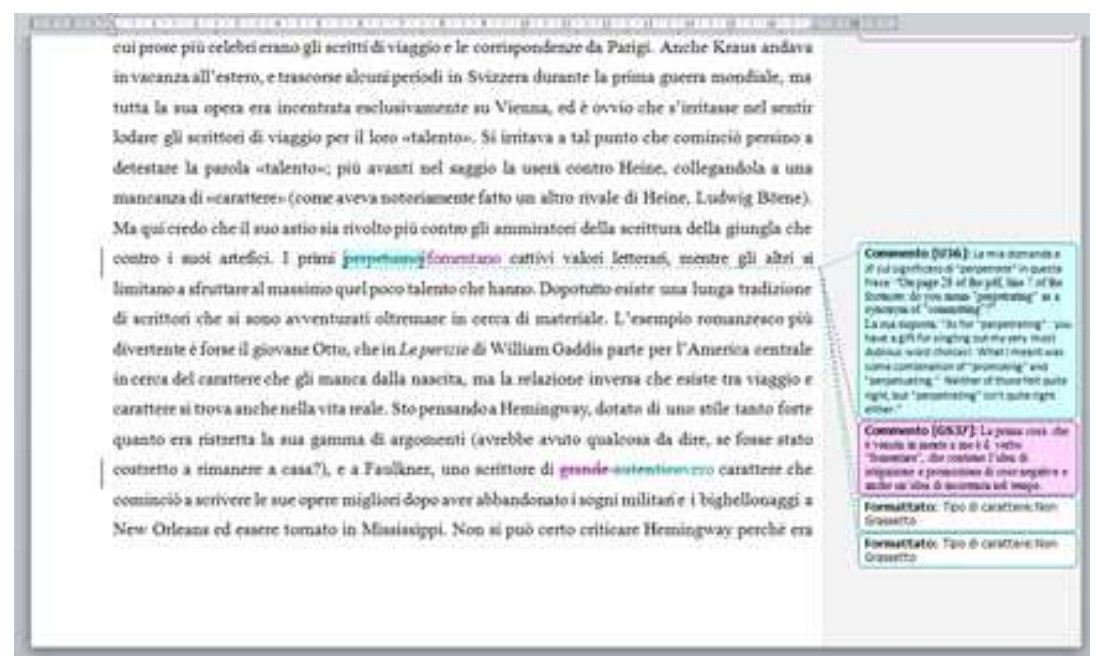

Figure 6: Author', translator' and reviser's comments.

From this brief selection of examples it should be clear how the professional practice of computer-based collaborative revision should be encouraged not only because it lays the foundations for fruitful and constructive translator/reviser relationships but also because it represents a valuable scholarly research tool, able to collect a wealth of qualitative and quantitative data on the revision process, its interim and final products and the attitudes/emotions/stances of the agents involved. It should be also clear, however, that the space and functionalities offered by Microsoft Word Revision may not be up to the task. In the following paragraphs a selection will be illustrated of other editing, tracking and commenting tools that can be beneficially applied to collaborative revision within a genetic perspective, thus enhancing and complementing those already available to translators and revisers.

\section{How editing, commenting and collaborative information technology can positively contribute to translation genetics research.}

The aim of this section is to outline the main assets some editing, commenting and collaborative IT tools have to offer to translation genetics research when applied to collaborative revision.

First of all, computer-based tools that can be used in collaborative revision fall by and large into three categories:

- $\quad$ Editing tools (for actual work on the text and its tracked-record) 
- Commenting tools (to annotate a text by adding pre-defined or personal comments)

- Collaborative tools (to create virtual places or platforms where collaborative work is possible)

Many of these tools include both editing and commenting features, much less present in the collaborative tools. What they all have in common, though, is the potential to improve and facilitate individual and collaborative revision, by producing at the same time user-friendly, easyto-use, tracked records for translation genetics research. Here follows a brief illustration of selected tools and their added value to translation genetics, well knowing there is still a lot to be explored and possibly developed.

As far as editing tools are concerned, the data collected through the survey illustrated in section 4 show that Microsoft Word Revision Tool is the most widespread and used among translators and revisers alike. However, some of its functionalities can be improved, upgraded or customized. Although textual change tracking is one of the most important features for a revision output to be effectively used in any translation genetics research, it may happen that no revision tool or change-tracking facility has been used during the revision stage. A much user-friendlier option than the Microsoft Word Compare Documents function is provided by Changetracker (http://change-tracker.com), a change-tracking freeware described in the official website as a tool "for tracking changes in bilingual documents. It can compare many file formats, can visualize the edits to speed up self-proofreading, streamline the linguistic quality assessment, and easily provide the evidence of TEP to stay compliant with the client and regulatory requirement." It is mainly intended for translation service providers and localization agencies, but it can be used with any kind of text.

In terms of commenting tools, what is already provided within Microsoft Word Revision Tool can be enhanced by adding macros, i.e. program add-ins that can be easily installed as part of Microsoft Word. One of these is CommentAddMenu (available from the free downloadable book Macros for Editors, at www.archivepub.co.uk/TheBook), a very useful tool which allows to choose a comment from a pre-defined, yet customizable, menu. Adding a pre-determined comment, moreover, does not prevent from typing additional text within the comment box. What seems particularly interesting of this tool in a translation genetics perspective is that it may foster and boost translator-reviser communication as it saves typing time and effort. In addition to this the comment, being pre-defined, is offered to the researcher with a sort of "identification tag", a key to readily interpret and understand the textual intervention it refers to and the rationale behind it, leaving much less room for speculation. A similar tool, allowing to tag the text with labels and adding comments, is called 
Proofreader Marks Add-in and is available at the following address: http://gregmaxey.mvps.org/word_tip_pages/proofreader_marks_addin.ht $\mathrm{ml}$

When working on pdf files, the Adobe Acrobat Commenting tool provides an interesting alternative to Microsoft Word Revision. What is especially good about comments, here, is that they are presented in chronological order and can be replied to without having to add a new one. Moreover, comments from the same person can be grouped and viewed separately. This diachronous presentation of the translator-reviser interplay seems particularly important when wanting to outline the progress through the various stages towards publication.

Commenting is taken several steps ahead with Co-ment (www.coment.com), a "web service for annotating, discussing and writing texts online". Its main assets are compatibility with many document formats for high quality import and export, but most of all, as advertised on the website, "you can edit your text, taking in account modification proposals from commentators [...] Co-ment allows version management. You can switch back to a previous version any time and visualize changes between any two versions. When you create a new one, you can keep the received comments or discard them." In other words, these feature provides a sort of built-in archival system which any translation genetics research would greatly benefit from.

The last category is that of the collaborative tools, that is virtual places or platforms where collaborative writing/editing/revision work is made possible. The difference with the commenting tools presented so far, is that these platforms allow for real-time, online collaboration. One of them is Piratepad (http://piratepad.net/C5uG0scJot), described as "a web based word processor designed for working collaboratively in real time". An alternative platform is provided by Etherpad (http://etherpad.org/), advertised on its website as "a highly customizable Open Source online editor providing collaborative editing in really realtime." The idea behind both platforms is to provide users with very basic text tools (barred or underlined text) to be used on a "pad" where the actual editing takes place. These tools are only visual and serve as prompts for the discussion and further comments that can take place in the form of a "chat". The creator of the pad can invite colleagues and commentators to join the platform and interact in real-time like in any other social network. A further available option is provided by Wordbee (http://www.wordbee.com/). It introduces itself as a "web-based collaborative translation management system" and it is originally meant for translation service providers working on large technical and specialized translation projects involving machine translation and collaborative translation/revision work. As for collaborative translation in particular, this "cloud technology" allows all the different participants of the translation cycle to collaborate in the same document, at the same time. It's easy to see how this represents an added value to investigation 
in translation/revision genetics, because any professional figure involved in the process of translation publishing may have a say on the process and his/her point of view or textual change will be registered in real-time. Moreover, real-time, on-line translator-reviser interaction may produce different and/or complementary results compared to off-line communication during the revision stage and it may also affect the revision process and product, and the relationships between the revision agents.

A newly developed platform, for specific use in literary translation, is TLHub - acronym for Translation and Literary Hub (http://tlhub.org/). It is supported, among others, by the European Society of Authors, the French Centre National du Livre, and the European associations of translators. It was officially launched in November 2013 in NY and introduced as a hands-on, online workshop during the 30th edition of the Assises de la Traduction Littéraire in Arles, France, where authors Bernard Hœpffner and Camille de Toledo translated, revised and commented Melville's Moby Dick. On TLhub, translators from all over the world can create an account and upload their work for other translators to revise or comment upon. As a translator, you can either choose to upload your project in a private domain and invite other users to work with you, or you can allow others to publicly follow your project and comment on the different paragraphs in your translation. The focus of this platform is the social aspect of translation, the idea of creating a networking community, and the protection of authorship. Editing tools being very limited, revision work is here much less "corrective" in approach and much more "constructive". Revision basically takes place as an exchange of comments, suggestions, explanations among peers, be them translation students or translation professionals. It can be effectively employed to create a collective memory of translations to be used as an archive both for professional purposes and for academic ones.

\section{Conclusions and future developments}

This paper dealt with revision as a key stage in any writing process. Although literary trends and the progress of technology have deeply affected the way revision is done, its role in the genesis of a text has not changed. When speaking of translation in particular, "interim versions", as well as other records of the creative process, have been indicated as precious, underexploited material for the study of the translation process and the translator's decision-making activity. The other-revision stage has been indicated as the place and time of negotiation par excellence, where translator' and reviser's views, choices and solutions may clash, thus hindering the progress of the translated text, or coincide, thus moving the translated text a step forward towards publication. While manuscripts or drafts, tend to be difficult to analyze and therefore pose methodological 
problems in research, computer-based collaborative revision can leave a trace on the translation work and thus produce a wealth of research material if we are to study both the translation process and its product.

A brief selection of editing, commenting, and collaborative tools currently available was provided to prove their beneficial application in the professional context, but most of all to stress their potential as means of data elicitation and collection in the field of translation genetics. Given the ever-growing offer of computer-based tools and applications, the development of ad-hoc solutions to be specifically employed in translation genetics might be a market reality. Editing, commenting and collaborative functionalities already available might be enhanced and complemented by other assets that best meet documentary and recording needs. In addition to change-tracking and real-time commenting, it might be interesting, for example, to record and view the chronology of all textual interventions and comments, in order to follow each step forward or backward during revision, and also to fully understand to what extent textual changes are the result of second thoughts or heated debate.

Finally, a need might arise for a comparative evaluation of computer-based tools according to various indicators (editing, changetracking, commenting features, user-friendliness, visual impact, range of applicability, level of customization, intrusiveness, emotional impact, potential for improvement, costs) and for studies on the way different methods and tools of textual intervention during the revision stage may affect the translation process and product and the translator-reviser relationship. Translation genetics can surely benefit from advances in such computer-based tools and their application to collaborative revision, as this paper has hopefully contributed to underline.

\section{References}

Allal, L., Chanquoy, L., \& Largy, P. (2004). Revision: Cognitive and instructional processes. Dordrecht: Kluwer Academic.

Barbosa, H. G., \& Neiva A. (2003). Using think-aloud protocols to investigate the translation process of foreign language learners and experienced translators. In F. Alves (Ed.), Triangulating translation: Perspectives in process oriented research (pp. 137-155). Amsterdam: John Benjamins.

Basso, S. (2010). Sul tradurre: Esperienze e divagazioni militanti. Milan: Bruno Mondadori Editore.

Bisaillon, J. (Ed.). (2007). La révision professionnelle: Processus, stratégies et pratiques. Québec, QC: Éditions Nota Bene.

Bogic, A. (2010). Uncovering the hidden actors with the help of Latour: The 'making' of the second sex. MonTI. Monografías de Traducción e Interpretación, 2 , 173-192.

Breedveld, H. (2002). Writing and revising process in professional translation. Across Languages and Cultures, 3(1), 91-100. 
Brunette, L. (2000). Towards a terminology for translation quality assessment: A comparison of TQA practices. The Translator, 6(2), 169-182.

Bryant, J. (2002). The fluid text: A theory of revision and editing for book and screen. Ann Arbor, MI: The University of Michigan Press.

Buzelin, H. (2007). Translations in the 'making'. In M. Wolf \& A. Fukari (Eds.), Constructing a sociology of translation (pp. 135-169). Amsterdam: John Benjamins.

Carmignani, I. (2008). Gli autori invisibili: Incontri sulla traduzione letteraria. Lecce: Besa.

Chakhachiro, R. (2005). Revision for quality. Perspectives: Studies in Translatology, 13(3), 225-238.

Chesnet, D., \& Alamargot, D. (2005). Analyses en temps réel des activités oculaires et graphomotrices du scripteur: Intérêt du dispositif 'Eye and Pen'. L'Année Psychologique, 105(3), 477-520.

Chesterman, A., Dam, H.V., Engberg, J., \& Schjoldager, A. (2003). Bananas - or names and definitions in translation studies. Hermes, Journal of Linguistics, 31, 197-209.

De Biasi, P-M. (2007). What is a literary draft?: Towards a functional typology of genetic documentation. Item. Retrieved from http://www.item.ens.fr/index.php?id=13599.

De Biasi, P-M. (2011). La genetica testuale. Translated into Italian by Chiara Montini. Rome: Aracne Editrice.

Delisle, J. (1988). Translation: An interpretative approach. Ottawa, ON: University of Ottawa Press.

Deppman, J., Ferrer, D., \& Groden, M. (Eds.). (2004). Genetic criticism: Texts and avant-textes. Philadelphia, PA: University of Pennsylvania Press.

Englund Dimitrova B. (2005). Expertise and explicitation in the translation process. Amsterdam: John Benjamins.

Filippalopoulou, M. (2008). Translation drafts and the translating self. In P. Nikolaou \& M.V. Kyrtsi (Eds.), Translating selves: Experience and identity between languages and literatures (pp. 19-36). London: Continuum.

Fordoński, K. (2014). The art of translation and the art of editing. Komunikacja Specjalistyczna, 7, 167-173.

Gile, D. (1995). Basic concepts and models for interpreter and translator training. Amsterdam: John Benjamins.

Göpferich, S., \& Jääskeläinen, R. (2009). Process research into the development of translation competence: Where are we, and where do we need to go?. Across Languages and Cultures, 10(2), 169-191.

Hansen, G. (2009a). The speck in your brother's eye - the beam in your own: Quality management in translation and revision. In G. Hansen, A. Chesterman, \& H. Gerzymisch-Arbogast (Eds.), Efforts and models in interpreting and translation research: A tribute to Daniel Gile (pp. 255-280). Amsterdam: John Benjamins..

Hansen, G. (2009b). A classification of errors in translation and revision. In M. Forstner, H. Lee-Jahnke, \& P. Schmit (Eds.), CIUTI Forum 2008. Enhancing translation quality: Ways, means, methods (pp. 313-326). Bern: Peter Lang. 
Hansen, G. (2010). Integrative description of translation processes. In G. M. Shreve \& E. Angelone (Eds.), Translation and cognition (pp. 189-211). Amsterdam: John Benjamins.

Hansen, G. (2013). Many tracks lead to the goal: A long-term study on individual translation styles. In C. Way, S. Vandepitte, R. Meylaerts, \& M. Bartlomiejczyk, (Eds.), Tracks and treks in translation studies (pp. 49-62). Amsterdam: John Benjamins.

Harris, T. L., \& Hodges, R. E. (Eds.). (1995). The literacy dictionary: The vocabulary of reading and writing. Newark, DE: International Reading Association.

Hay, L. (1988). Does 'text' exist? Studies in Bibliography, 41, 64-76.

Hayes, J. R., \& Flower, L. S. (1980). Identifying the organization of writing processes. In W. Gregg \& R. Steinberg (Eds.). Cognitive processes in writing (pp. 3-30). Hillsdale, NJ: Lawrence Erlbaum.

Hayes J. R. (1996). A new framework for understanding cognition and affect in writing. In C. M. Levy \& S. Ransdell (Eds.), The science of writing (pp. 127). Mahwah, NJ: Lawrence Erlbaum.

Hernández Morin, K. (2009a). Pratiques et perceptions de la révision en France. Traduire, 2(221), 58-78.

Hernández Morin, K. (2009b). La révision comme clé de la gestion de la qualité des traductions en contexte professionnel. (Unpublished doctoral dissertation). Retrieved from: http://tel.archivesouvertes.fr/docs/00/38/32/66/PDF/TheseMorinHernandez.pdf

Hine, J. T. (2003). Teaching text revision in a multilingual environment. In B. J. Baer, \& G.S. Koby (Eds.), Beyond the ivory tower: Rethinking translation pedagogy (pp. 135-156). Amsterdam: John Benjamins.

Holmes, J. S. (1972). The name and nature of translation studies. In L. Venuti (Ed.), Translation studies reader (pp. 173-185). London: Routledge.

Horguelin, P. A., \& Brunette, L. (1998). Pratique de la révision. Brossard, QC: Linguatech.

Horning A., \& Becker A. (Ed.). (2006). Revision: History, theory and practice. West Lafayette, IN: Parlor.

Horning, A. S. (2002). Revision revisited. Cresskill, NJ: Hampton.

Jones, F. (2006). Unlocking the black box: Researching poetry translation processes. In M. Perteghella \& E. Loffredo (Eds.), Translation and creativity: Perspectives on creative writing and translation studies (p. 59-74). London: Continuum.

Kolb, W. (2013). Who are they?: Decision-making in literary translation. In C. Way, S. Vandepitte, R. Meylaerts, \& M. Bartlomiejczyk, (Eds.), Tracks and treks in translation studies (pp. 207-221). Amsterdam: John Benjamins.

Kruger, H. (2008). Training editors in universities: Considerations, challenges and strategies. In J. Kearns (Ed.), Translator and interpreter training: Issues, methods and debates (pp. 39-65). London: Continuum.

Künzli, A. (2005) What principles guide translation revision?: A combined product and process study. In I. Kemble (Ed.), Translation norms: What is 'normal' in the translation profession? Proceedings of the 4th Translation Conference, 
University of Portsmouth, November 2004 (pp. 31-44). Portsmouth: University of Portsmouth, School of Languages and Area Studies.

Künzli, A. (2006). Teaching and learning translation revision: Some suggestions based on evidence from a think-aloud protocol study. In M. Garant (Ed.), Current trends in translation teaching and learning (pp. 9-24). Helsinki: Department of Translation Studies.

Künzli, A. (2007a). Translation revision: A study of the performance of ten professional translators revising a legal text. In Y. Gambier, M. Shlesinger, \& R. Stolze (Eds.), Doubts and directions in translation studies: Selected contributions from the EST Congress, Lisbon 2004 (pp. 115-126). Amsterdam: John Benjamins.

Künzli, A. (2007b). The ethical dimension of translation revision: An empirical study. Journal of Specialized Translation, 8, 42-56.

Künzli, A. (2009). Qualität in der Übersetzungsrevision: Eine empirische Studie. In H. Kalverkämper \& L.Schippel (Eds.), Translation zwischen Text und Welt: Translationswissenschaft als historische Disziplin zwischen Moderne und Zukunft (pp. 291-303). Berlin: Frank \& Timme.

Künzli, A. (2014). Die Übersetzungsrevision: Begriffsklärungen, Foschungsstand, Forschungsdesiderate. Trans-kom, 7(1), 1-29.

Lee, H. (2006). Révision: Définitions et paramètres. Meta, 51(2), 410-419.

Manfrinato, C. (Ed.). (2008). Il mestiere di riflettere. Rome: Azimut.

Marco, J. (2007). The terminology of translation: Epistemological, conceptual and intercultural problems and their social consequences. Target, 19(2), 255-269.

Mossop, B. (1992). Goals of a revision course. In C. Dollerup \& A. Loddegaard (Eds.), Teaching translation and interpreting: Training, talent and experience - Papers from the First Language International Conference, Elsinore, Denmark, 1991 (pp. 81-90). Amsterdam: John Benjamins.

Mossop. B. (2001). Revising and editing for translators. Manchester: St. Jerome.

Mossop. B. (2014). Revising and editing for translators. $3^{\text {rd }}$ Edition. Abingdon: Routledge.

Mossop, B. (2015). Readings on revision and editing. Online publication retrieved from http://www.yorku.ca/brmossop/RevisionBiblio.htm

Munday, J. (2001). Introducing translation studies: Theories and applications. London: Routledge.

Munday, J. (2013). The role of archival and manuscript research in the investigation of translator decision-making, Target, 25(1), 125-139.

Nida, E. A. (1964). Towards a science of translating: With special reference to principles and procedures involved in bible translating. Leiden: E.J.Brill.

Parra Galiano, S. (2007a). La revisión y otros procedimientos para el aseguramiento de la calidad de la traducción: Grados, tipos y modalidades de revisión. Senez, $32,97-122$.

Parra Galiano, S. (2007b). Propuesta metodológica para la revisión de traducciones: Principios generales y parámetros. Trans, 11, 197-214.

Paul, G. (Ed.). (2009). Translation in practice: A symposium. Champaign: Dalkey Archive. 
Pavlović, N. (2009). More ways to explore the translating mind: collaborative translation protocols. In S. Göpferich, A. L. Jakobsen, \& I. M. Mees (Eds.), Behind the mind: Methods, models and results in translation process research (pp. 81-105). Copenhagen: Samfundslitteratur.

Pavlović, T. (2013). The role of collaborative translation protocols (CTPs) in translation studies. Jezikoslovlje, 14(2-3), 549-563.

Petruccioli, D. (2014). Falsi d'autore: Guida pratica per orientarsi nel mondo dei libri tradotti. Macerata: Quodlibet.

Pym, A. (2011). Translation research terms: A tentative glossary for moments of perplexity and dispute. Translation Research Projects 3, Tarragona: Intercultural Studies Group, 75-110. Retrieved from: http://isg.urv.es/publicity/isg/publications/trp_3_2011/index.htm

Reiss, K. (2000). Translation criticism - The potentials and limitations. Categories and criteria for translation quality assessment. Manchester: St. Jerome.

Robert, I. (2008). Translation revision procedures: An explorative study. In Translation and its Others: Selected papers of the CETRA Research Seminar in Translation Studies 2007. Online resource retrieved from: http://www.arts.kuleuven.be/cetra/papers/files/robert.pdf.

Robert, I. (2012). La révision en traduction: Les procedures de révision et leur impact sur le produit et le processus de révision. (Unpublished doctoral dissertation) Retrieved

from: http://www.alineremael.be/data/These_ISBN_20120425_BW.pdf

Robert, I. (2013). Translation revision: Does the revision procedure matter? In C. Way, S. Vandepitte, R. Meylaerts, \& M. Bartlomiejczyk, (Eds.), Tracks and treks in translation studies: Selected papers from the EST Congress, Leuven 2010 (pp. 87-102). Amsterdam: John Benjamins,.

Robert, I. (2014). Investigating the problem-solving strategies of revisers through triangulation: An exploratory study. Translation and Interpreting Studies. The Journal of the American Translation and Interpreting Studies Association, $9(1), 88-108$.

Rochard, M. (2002). La révision: Un acte pédagogique et économique. Online resource retrieved from: http://pagespersoorange.fr/michel.rochard/textes/rennes_2002.pdf

Romanelli, S. (2013). Gênese do processo tradutório. Vinhedo: Horizonte.

Roussey, J. Y., \& Piolat, A. (2008). Critical reading effort during text revision. European Journal of Cognitive Psychology, 20(4), 765-792.

Schjoldager, A., Rasmussen, K. W., \& Thomsen, C. (2008). Précis-writing, revision and editing: Piloting the European Master in Translation. Meta, 53(4), 798813.

Séguinot, C. (1991). A study of student translation strategies. In S. Tirkkonen-Condit (Ed.), Empirical research in translation and intercultural studies (pp. 79-88). Tübingen: Narr.

Scocchera, G. (2015). La revisione della traduzione editoriale dall'inglese all'italiano tra ricerca accademica, professione e formazione: Stato dell'arte $e$ prospettive future. (Unpublished doctoral dissertation). University of Bologna, Forlì Campus. 
Shih, C. (2006). Revision from translators' point of view: An interview study. Target, $18(2), 295-312$.

Siponkoski, N. (2013) Translators as negotiators: A case study on the editing process related to contemporary Finnish translation of Shakespeare. New Voices in Translation Studies, 9, 20-37.

Sorvali, I. (1998). The translator as creative being with special regard to the translation of literature and LSP. Babel, 44(3), 234-243.

Šunková, J. (2011). Revising translations: Corpus investigation of revision and selfrevision. (Unpublished doctoral dissertation). Retrieved from http://is.muni.cz/th/362729/ff_m/DIPLOMOVA_PRACE_SUNKOVA.pdf

Toury, G. (1980). In search of a theory of translation. Tel Aviv: The Porter Institute of Poetics and Semiotics.

Toury, G. (1995). Descriptive translation studies and beyond. Amsterdam: John Benjamins.

1 Translation studies terminology, and revision terminology in particular, is a field of research in its own right. If there is full agreement on the need for a shared translation studies terminology (e.g., Chesterman et al., 2003; Marco, 2007), revision terminology is still extremely varied. While contributions from Horguelin and Brunette (1998), Mossop (2001/2014), Pym (2011), and more recently Künzli (2014) and Scocchera (2015), represent an important starting point for an overview of revision terminology, the different uses and acceptations of revision-related terms in theoretical and practical contexts still mostly overlap, partly hindering semantic accuracy.

2 An exhaustive and up-to-date review of scholarly literature on revision is found in some recently defended PhD theses (Hernández-Morin, 2009b; Robert, 2012; Šunková, 2011), in monographic essay selections (Bisaillon, 2007) and in articles specifically aimed at illustrating the state of the art in revision research (Künzli, 2014; Mossop, 2015). 